\title{
Fruit internal brown rot caused by Neoscytalidium dimidiatum on pitahaya in Guangdong province, China
}

\author{
Run Hua $\mathrm{Yi}^{1} \cdot$ Qiao ling lin ${ }^{1} \cdot$ Jun Jie Mo ${ }^{1}$. \\ Feng Fa Wu ${ }^{1} \cdot$ Jing Chen ${ }^{1}$
}

Received: 9 November 2013 / Accepted: 24 March 2015 / Published online: 8 April 2015

(C) Australasian Plant Pathology Society Inc. 2015

\begin{abstract}
In July 2013, an unknown fruit internal brown rot disease was observed on white-fleshed pitahaya (Hylocereus undatus) in Zhanjiang, Guangdong province, China. Based on morphological characteristics and phylogenetic analysis of ITS sequences, the pathogen was determined as Neoscytalidium dimidiatum.
\end{abstract}

Keywords Hylocereus $\cdot$ Fungal diseases $\cdot$ Neoscytalidium dimidiatum

Pitahaya (Hylocereus undatus), also known as strawberry pear or dragon fruit, is a cactaceous fruit crop cultivated widely in some tropical and subtropical countries because of its high nutrient content and numerous selling points such as the attractive shape, colour and the good internal properties for market (Le Bellec et al. 2006). In China, pitahaya is a great contributor to the regional farming economic development particularly in the Hainan, Guangdong, Fujian, Guangxi and Yunnan provinces; the cultivation area up to 13,000 ha on the mainland.

In July 2013, an unknown fruit internal brown rot disease was observed on white-fleshed pitahaya in several orchards of Zhanjiang, Guangdong province. The disease caused the fruit to develop slower than uninfected fruit in the initial stage, induced fruit internal brown rot and made the peel colour change from green to red 10-15 days in advance of the normal fruit peel which turned red 24-25 days after anthesis (Nerd et al. 1999). The brown rot first occurred below the persistent

Run Hua Yi

scibyrh@163.com

1 Department of biotechnology, Agricultural College, Guangdong Ocean University, Zhanjiang 524088, Guangdong Province, China style (Fig. 1a) which gradually spread and developed into a rotten area. The conspicuous grey-white mycelia developed after the diseased fruit was cut in half lengthways and kept in a sealed plastic box for 3 days (Fig. 1b). The incidence of the disease was approximately $15 \%$ in the field.

Fruit with internal brown rot were collected from an orchard $\left(21^{\circ} 8^{\prime} 52^{\prime \prime} \mathrm{N} 110^{\circ} 18^{\prime} 28^{\prime \prime} \mathrm{E}\right)$. After surface sterilisation with $75 \%$ ethanol solution, a symptomatic piece of fruit tissue from the location of the brown rot was carefully extracted with sterile forceps and placed on potato dextrose agar (PDA) plates under aseptic conditions and then incubated at $25{ }^{\circ} \mathrm{C}$ in the dark for $36 \mathrm{~h}$. Hyphae growing from the tissue pieces were transferred and sub-cultured to obtain pure cultures. To obtain single spored isolates, conidia from pure cultures were suspended in sterile water and streaked onto PDA plates. The single-conidia forming colonies were obtained after incubation at $25^{\circ} \mathrm{C}$ in the dark for $24 \mathrm{~h}$.

Healthy fruit were used for pathogenicity tests in the laboratory and field. A suspension of approximately $10^{4}$ spores/ $\mathrm{mL}$ was prepared from 4-day-old cultures grown at $25^{\circ} \mathrm{C}$ in the dark. Two hundred $\mu$ l of the suspension was injected into the sarcocarp of healthy fruit with a sterile $32 \mathrm{G}$ hypodermic needle. Injection of isovolumetric sterile water served as a control. In the laboratory, all fruit were maintained in a sealed plastic box at $25^{\circ} \mathrm{C}$ in the dark. The symptoms of brown rot were observed on inoculated fruit 7 days postinoculation (Fig. 1c). Fruit in the laboratory rotted more quickly than in the field, whereas control fruit did not develop any symptoms (Fig. 1d). The same fungi were subsequently re-isolated from the rotten tissues which confirmed the disease aetiology.

Fungal isolates grew quickly on PDA and the colony diameter reached up to $7.2 \pm 0.5 \mathrm{~cm}$ at $25{ }^{\circ} \mathrm{C}$ in the dark after 3 days. The colony was covered with dense, grey to black, cottony aerial mycelia. Colony colour originally was greywhite, and gradually became black on reverse and obverse 
Fig. 1 Symptoms of fruit flesh brown rot disease and the causative agent of Neoscytalidium dimidiatum. a Vertical section of diseased fruit, the flesh brown rot on the top. b Grey mycelia growing from the surface of diseased flesh after 3 days incubation in a sealed plastic box. c Artificial inoculation with spore suspension. d Artificial inoculation with sterile water. $\mathbf{e}$ and $\mathbf{f}$ Colony of $N$. dimidiatum on PDA, e Incubation for 5 days and f for 15 days at $25^{\circ} \mathrm{C}$ in the dark. $\mathbf{g}$ and $\mathbf{h}$ Chains of arthroconidia. $\mathbf{i}$ and $\mathbf{j}$ The size-and-shape-variable arthroconidia, (i) Incubation for 5 days and (j) for 15 days at $25^{\circ} \mathrm{C}$ in the dark. Scale bars: (g), (h), (i) $=10 \mu \mathrm{m},(\mathbf{j})=20 \mu \mathrm{m}$
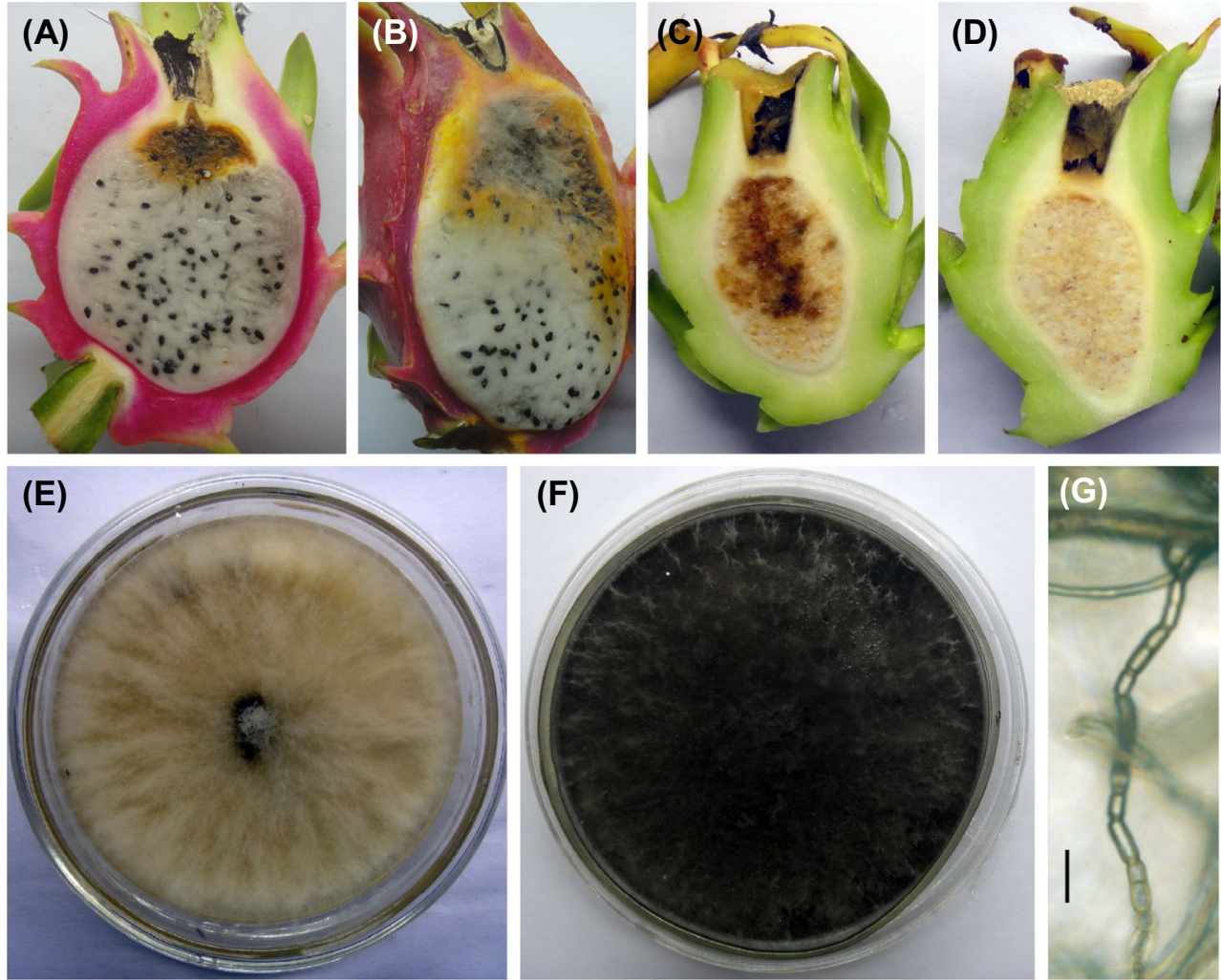

(F)
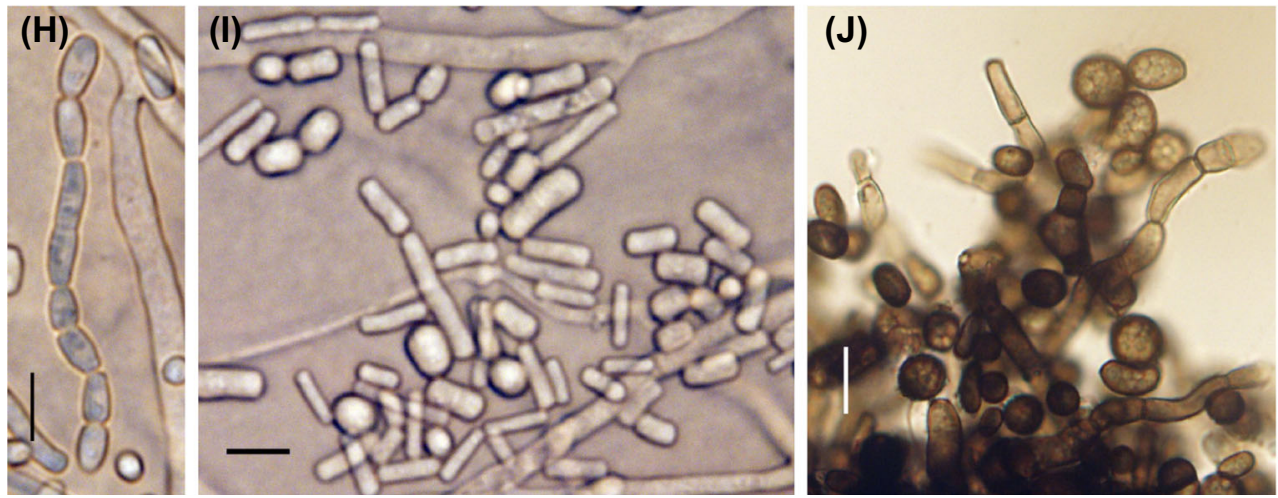

sides of Petri dishes (Fig. 1e and f). Mycelia were branched, septate, hyaline to brown hyphae which constricted into spore chains (Fig. 1g and h) and disarticulated into arthroconidia. The arthroconidia were orbicular to dolioform, hyaline to dark brown, thick-walled, and 0-1-septate, 2.64-6.75 (av. 4.39 \pm $0.88) \times 3.61-22.87$ (av. 8.72 \pm 2.62$) \mu \mathrm{m}(\mathrm{n}>50)$ (Fig. 1i and g)

A representative isolate, ACCC 38865 , was selected for sequencing and phylogenetic analysis and deposited with Agricultural Culture Collection of China (ACCC). The internal transcribed spacer (ITS1-5.8S-ITS2) sequence was amplified using ITS1 (TCC GTA GGT GAA CCT GCG G) and ITS4 (TCC TCC GCT TAT TGA TAT GC) (White et al. 1990) according to the method of Lu et al. (2012). The sample was denatured at $98{ }^{\circ} \mathrm{C}$ for $5 \mathrm{~min}$, followed by 40 amplification cycles $\left(98^{\circ} \mathrm{C}\right.$ for $10 \mathrm{~s}, 56^{\circ} \mathrm{C}$ for $15 \mathrm{~s}, 68^{\circ} \mathrm{C}$ for $\left.1 \mathrm{~min}\right)$ and a final extension $\left(68{ }^{\circ} \mathrm{C}\right.$ for $\left.10 \mathrm{~min}\right)$. The PCR amplification product was sequenced at the Sangon Biotech (Shanghai, China) Co., Ltd. A new sequence of 574 bp was obtained and deposited in GenBank (KF812550). The sequence was blasted with the sequences deposited in GenBank nucleotide database and the results showed greater than $99 \%$ similarity to sequences of Neoscytalidium dimidiatum (KF000372, JX524168, JX473739 and HQ439174).

For the phylogenetic analysis, a total of 32 sequences of Neoscytalidium and Scytalidium species obtained from GenBank and ACCC38865 were used to construct the 
Fig. 2 Molecular phylogenetic analysis of isolate ACCC 38865 with Neoscytalidium spp. and Scytalidium spp. obtained from GenBank by Maximum Likelihood method based on the ITS sequences. Bootstrap values after 1000 replicates were expressed as percentages

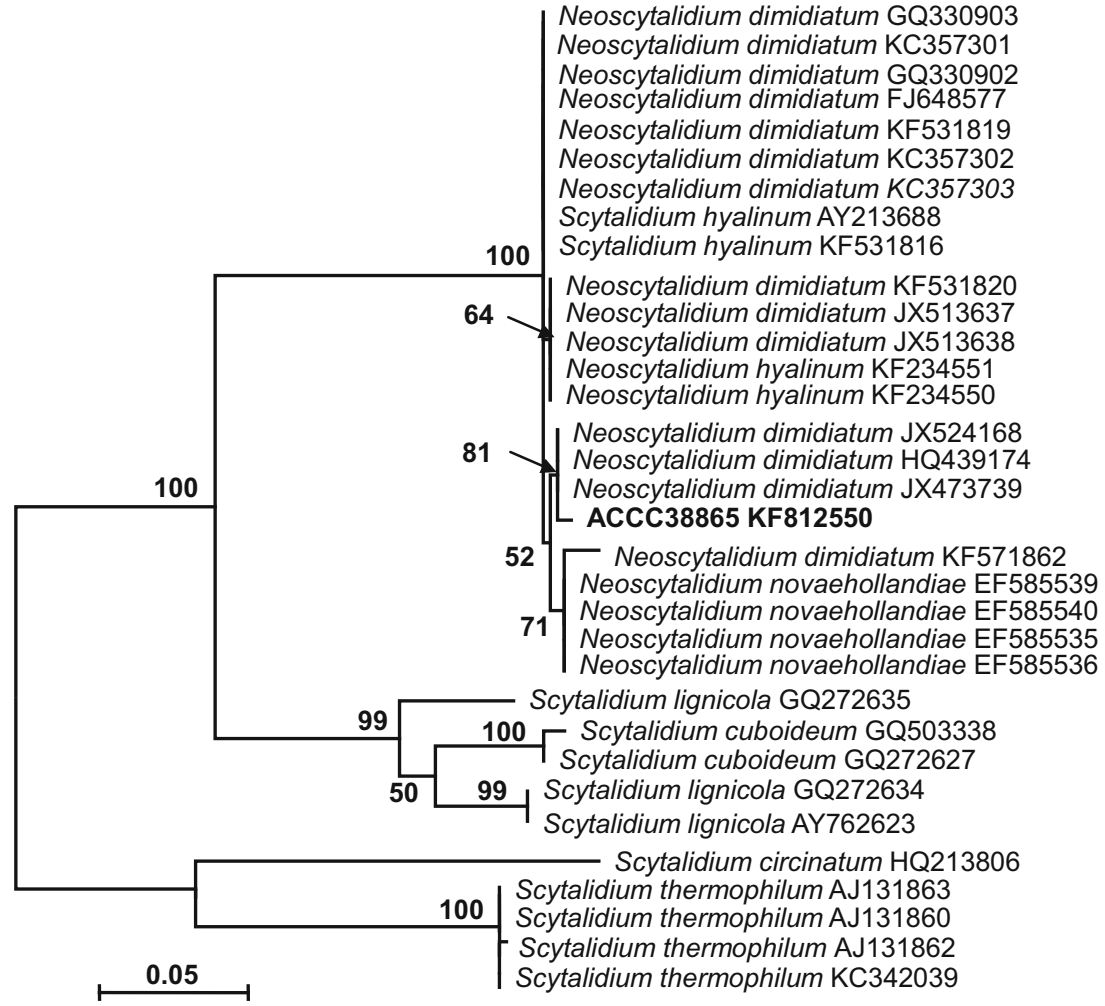

Neoscytalidium dimidiatum GQ330903

Neoscytalium dimidiatum KC357301 Neoscytalidium dimidiatum FJ648577

Neoscytalidium dimidiatum KF531819



Scytalidium hyalinum AY213688 Scytalidium hyalinum KF531816

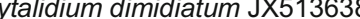

Neoscytalidium dimidiatum JX524168

(2)

(1) Neoscytalidium novaehollandiae EF585539 (5)

Neoscytalidium novaehollandiae EF585535

Neoscytalidium novaehollandi Scytalidium cuboideum GQ503338

Scytalidium lignicola AY762623 Scytalidium circinatum HQ213806 Scytalidium thermophilum AJ131862

phylogenetic tree. Nucleotide sequences were analysed using MEGA version 6 (Tamura et al. 2013) for Maximum Likelihood analyses, using the Kimura-2-parameter nucleotide substitution model. Bootstrap values were obtained from 1000 bootstrap replicates. The isolate ACCC38865 clustered in a clade with known isolates of $N$. dimidiatum, $N$. novaehollandiae and Scytalidium hyalinum with high bootstrap support (100\%), and in a subclade with three isolates of $N$. dimidiatum with $81 \%$ bootstrap support (Fig. 2). $S$. hyalinum was considered to be a variety or a melanindeficient cultural mutant of $N$. dimidiatum (Polizzi et al. 2011), and has never been isolated from plants or the environment (Machouart et al. 2004). Neoscytalidium novaehollandiae produced muriform, Dichomera-like conidia (Pavlic et al. 2008), which distinguished it from isolate ACCC38865. Therefore, the pathogen of fruit internal brown rot disease was identified as $N$. dimidiatum (Crous et al. 2006) based on the morphological characters as well as the ITS1-5.8S-ITS2 sequence.

Neoscytalidium dimidiatum is an opportunistic fungus of plants (Padin et al. 2005). This pathogen can cause pitahaya canker and spot on the surface of the stem or fruit (Lan et al. 2012; Chuang et al. 2012; Yi et al. 2013; Mohd et al. 2013) and internal black rot in fruit (Ezra et al. 2013). However, this is the first reported of internal browning in pitahaya in Guangdong Province, China.

\section{References}

Chuang MF, Ni HF, Yang HR, Shu SL, Lai SY, Jiang YL (2012) First report of stem canker disease of Pitaya (Hylocereus undatus and H. polyrhizus) Caused by Neoscytalidium dimidiatum in Taiwan. Plant Disease 96(6):906. doi:10.1094/pdis-08-11-0689-pdn

Crous PW, Slippers B, Wingfield MJ, Rheeder J, Marasas WFO, Philips AJL, Alves A, Burgess T, Barber P, Groenewald JZ (2006) Phylogenetic lineages in the Botryosphaeriaceae. Studies in Mycology 55(1):235-253. doi:10.3114/sim.55.1.235

Ezra D, Liarzi O, Gat T, Hershcovich M, Dudai M (2013) First report of internal black rot caused by Neoscytalidium dimidiatum on Hylocereus undatus (Pitahaya) fruit in Israel. Plant Disease 97(11): 1513. doi:10.1094/pdis-05-13-0535-pdn

Lan GB, He ZF, Xi PG, Jiang ZD (2012) First report of brown spot disease caused by Neoscytalidium dimidiatum on Hylocereus undatus in Guangdong, Chinese Mainland. Plant Disease 96(11): 1702. doi:10.1094/pdis-07-12-0632-pdn

Le Bellec F, Vaillant F, Imbert E (2006) Pitahaya (Hylocereus spp.): a new fruit crop, a market with a future. Fruits 61(4):237-250. doi:10. 1051/fruits:2006021

Lu Q, Hu H, Mo J, Shu L (2012) Enhanced amplification of bacterial and fungal DNA using a new type of DNA polymerase. Australasian Plant Pathology 41(6):661-663. doi:10.1007/ s13313-012-0144-4

Machouart M, Lacroix C, Bui H, Feuilhade de Chauvin M, Derouin F, Lorenzo F (2004) Polymorphisms and intronic structures in the 18S subunit ribosomal RNA gene of the fungi Scytalidium dimidiatum and Scytalidium hyalinum. FEMS Microbiology Letters 238(2): 455-467. doi:10.1111/j.1574-6968.2004.tb09789.x 
Mohd MH, Salleh B, Zakaria L (2013) Identification and molecular characterizations of Neoscytalidium dimidiatum causing stem canker of red-fleshed dragon fruit (Hylocereus polyrhizus) in Malaysia. Journal of Phytopathology 161(11-12):841-849. doi:10.1111/jph.12146

Nerd A, Gutman F, Mizrahi Y (1999) Ripening and postharvest behaviour of fruits of two Hylocereus species (Cactaceae). Postharvest Biology and Technology 17(1):39-45. doi:10.1016/S09255214(99)00035-6

Padin C, Fernández-Zeppenfeldt G, Yegres F, Richard-Yegres N (2005) Scytalidium dimidiatum: an opportunistic fungus for both man and Mangifera indica trees in Venezuela. Revista Iberoamericana de Micología 22(3):172-173

Pavlic D, Wingfield MJ, Barber P, Slippers B, Hardy GESJ, Burgess TI (2008) Seven new species of the Botryosphaeriaceae from baobab and other native trees in Western Australia. Mycologia 100(6):851866. doi: $10.3852 / 08-020$

Polizzi G, Aiello D, Castello I, Vitale A, Groenewald JZ, Crous PW (2011) Occurrence, molecular characterisation, and pathogenicity of Neoscytalidium dimidiatum on Citrus. In: Gentile A, La Malfa $\mathrm{S}$ (eds) Proceedings of the International Symposium on Citrus Biotechnology, Catania (Italy). pp 237-243. doi:http://www. actahort.org/books/892/892_27.htm

Tamura K, Stecher G, Peterson D, Filipski A, Kumar S (2013) MEGA6: Molecular Evolutionary Genetics Analysis Version 6.0. Molecular Biology and Evolution 30(12):2725-2729. doi:10.1093/molbev/ mst197

White TJ, Bruns T, Lee S, Taylor J (1990) Amplification and direct sequencing of fungal ribosomal RNA genes for phylogenetics. In: Innis M, Gelfand DH, Sninsky JJ, White TJ (eds) PCR Protocols: a guide to methods and applications. Academic Press Inc., New York, p 482

Yi RH, Gan LJ, Yan DH, Wu ZJ, Tong YT, Wu FF (2013) Identification and biological characteristics of Neoscytalidium dimidiatum causing pitaya canker disease. Acta Phytophylacica Sinica (Journal of Plant Protection) 40(2):102-108 